\title{
Aceitabilidade de barra de cereal com adição de okara e farelo de casca de abacaxi
}

\author{
Darlene Ana de Paula Vieira \\ Instituto Federal de Goiás (IFG) ï Campus Inhumas \\ (darlene.vieira@ifg.edu.br) \\ Maria Deluany Guilherme Duarte \\ Instituto Federal de Goiás (IFG) ï Campus Inhumas \\ (maria_dgd@hotmail.com) \\ Gabriel Brito Ribeiro \\ Instituto Federal de Goiás (IFG) ï Campus Inhumas \\ (gabrielbr_biel@hotmail.com)
}

\author{
Eli Regina Barboza de Souza \\ Universidade Federal de Goiás (UFG) \\ (eliregina1@gmail.com) \\ Rosângela Vera \\ Universidade Federal de Goiás (UFG) \\ (rosangela.vera@uol.com.br)
}

\begin{abstract}
Resumo: Este trabalho teve como objetivos elaborar e avaliar barras de cereais produzidas utilizando okara e farelo de casca de abacaxi, analisar as características físico-químicas, cor por imagem digital e análise sensorial deste produto. Foram desenvolvidas formulações, variando-se a porcentagem de okara e farelo de casca de abacaxi (10, 15 e $20 \%$ ) na composição das barras de cereais. As barras apresentaram pH variando de 5,24 a 5,55, acidez titulável de 0,54 a $0,56 \%$, sólidos solúveis totais de 68,50 a 69,00 , SST/AT de 122,46 a 126,90. A relação SST/AT é considerada um dos indicativos de maior importância para características do sabor de um alimento, sendo definido pelo balanço entre sólidos solúveis e acidez. A formulação F2 tendeu a uma coloração mais escura $\left(L^{*}\right)$, de acordo com as análises realizadas nas imagens digitais. Foi observada diferença significativa para o sabor entre as três formulações, não sendo verificadas diferenças significativas entre cor, consistência e impressão global. Quanto às análises sensoriais, as formulações foram bem aceitas pelos julgadores, atingindo-se altos índices de aceitabilidades para todos os atributos avaliados de cor, sabor, consistência e impressão global, ficando esse valor maior que 79,33\%. Com base nos resultados obtidos, podemos considerar as barras de cereais produzidas no presente trabalho como satisfatórias sob o ponto de vista da aceitabilidade pelo consumidor.
\end{abstract}

Palavras Chave: Acidez; sólidos solúveis; cor e sabor.

\section{Cereal Bar Acceptability with Added Okara and Pineapple Husk}

Abstract: The objectives of this work were to elaborate and evaluate cereal bars produced using okara and pineapple husk to analyze the physicochemical characteristics, color by digital image and sensory analysis of this product. Formulations were developed varying the percentage of okara and pineapple shell $(10,15$ and $20 \%$ ) in the composition of cereal bars. The bars presented pH ranging from 5.24 to 5.55 , titratable acidity from 0.54 to $0.56 \%$, total soluble solids from 68.50 to 69.00 , TSS/TA from 122.46 to 126.90 . The TSS/TA ratio is considered one of the most important indicative for the taste characteristics of a food, being defined by the balance between soluble solids and acidity. The F2 formulation tended to have a darker color $\left(\mathrm{L}^{*}\right)$ according to the analyses performed on the digital images. Significant differences in flavor were observed between the three formulations and no significant differences were found between color, consistency and overall impression. As sensory analysis, the formulations were well accepted by the judges, reaching high levels of acceptability for all evaluated attributes of color, flavor, consistency and overall impression leaving this value greater than 
$79.33 \%$. Based on the results obtained, we can consider the cereal bars produced in the present work as satisfactory from the point of view of consumer acceptability.

Key-words: Acidity; soluble solids; color and flavor.

\section{INTRODUÇÃO}

A busca por uma vida mais saudável impulsiona o consumo por produtos leves e naturais, como as barras de cereais. Por isso esses produtos apresentam uma forte tendência de crescimento no mercado. As primeiras barras de cereais foram comercializadas no Reino Unido, em meados da década de 80. No Brasil, sugiram em 1992 e eram consumidas principalmente por atletas. O consumo também ocorre por pessoas que desejam perder ou manter o peso ou aliar uma alimentação saudável à praticidade (RODRIGUES JUNIOR et al., 2011).

As barras de cereais são definidas por Lobato et al. (2012) como alimento nutritivo composto por vários ingredientes, que incluem cereais, frutas, nozes e açúcar. Os atributos de textura, sabor e propriedades físicas são definidos pela combinação adequada dos ingredientes, que devem se completar mutuamente, de modo a revelar um sabor adocicado e agradável (SOUZA et al., 2012).

A mudança do estilo de vida e dos hábitos alimentares dos indivíduos afeta a ingestão e as necessidades de nutrientes, por isso é importante que haja uma alimentação saudável e equilibrada, para atender as necessidades básicas do organismo. Neste contexto, a popularidade da barra de cereal está entre os mais sofisticados produtos consumidos, através de apelos como ñngredientes naturaisòe r̃saúdeò(GRDEN et al., 2008).

A demanda por alimentos nutritivos e seguros está crescendo mundialmente, e a ingestão de alimentos balanceados é a maneira correta de evitar ou mesmo corrigir problemas de saúde, como: obesidade, diabetes, desnutrição, cardiopatias, entre outros que têm origem, em grande parte, nos erros alimentares. Observa-se uma nova tendência no consumo alimentar, com uma demanda cada vez maior por alimentos com elevadas propriedades nutricionais e funcionais. As barras de cereais atendem a esta tendência e são elaboradas a partir da extrusão da massa de cereais de sabor adocicado e agradável, fonte de vitaminas, sais minerais, fibras, proteínas e carboidratos complexos (IZZO; NINESS, 2001). 
O processamento da barra ocorre em duas fases, a saber, a f̂ase sólidaò obtida da compactação de grãos (cereais e fabaceaes), nozes (castanhas e amêndoas) e frutas secas, em uma variedade de combinações, e a f̂ase contínuaò adicionada de substâncias ligantes, tais como mel, melado de cana, açúcar mascavo, sacarose, xarope de glicose, açúcar invertido, lecitina de soja, glicerina, pectina cítrica, óleos, gordura vegetal e outros (PAIVA, 2008).

As agroindústrias de alimentos vegetais, paralelamente à linha convencional de seus produtos, geram subprodutos e resíduos que ainda trazem considerável potencial nutritivo e de fibras. No caso do subproduto, tem-se buscado várias maneiras de agregar-lhe valores, tornando a sua comercialização economicamente mais viável (PAIVA, 2008). A viabilidade de utilização de subprodutos e resíduos de agroindústrias com agregação de valores para serem consumidos na alimentação humana tem sido constantemente investigada. Como a formulação de barras de cereais possibilita grande diversificação do produto, a utilização de resíduos pode contribuir tanto para agregar qualidade tecnológica e nutricional como também diminuir os impactos no ambiente (FONSECA et al., 2011).

$\mathrm{Na}$ elaboração de produtos do abacaxi, principalmente no processamento de abacaxi em calda, ocorre grande acúmulo de cascas, centros, aparas e outras partes não utilizadas pela agroindústria. A porção comestível representa apenas $22,5 \%$ a $35 \%$ do fruto, sendo o restante descartado. Esses resíduos, principalmente de cascas, obtidos durante o descasque mecânico do fruto contém quantidade considerável de polpa aderida, que é descartada juntamente com os outros resíduos. Tais resíduos servem apenas como material base para a alimentação animal (PRADO et al., 2003), não sendo utilizados para a obtenção de subprodutos.

O okara é um subproduto do processamento do extrato aquoso de soja e do tofu e contém aproximadamente $27 \%$ de proteínas (base seca) com boa qualidade nutricional; por este motivo é considerado uma fonte de proteína vegetal de baixo custo e que apresenta um bom potencial para consumo humano (APLEVICZ e DEMIATE, 2007). No entanto, O okara é utilizado mais comumente na fabricação de rações para animais ou descartado como ñixo industrialò contaminando o meio ambiente (SILVA et al., 2007). Contudo, o okara tem sido proposto como um ingrediente funcional por ser rico em proteínas e em lipídios, apresentar componentes como os ácidos graxos (PAULA et al., 2019). 
Com base no exposto, o presente trabalho teve como objetivos elaborar e avaliar barras de cereais produzidas utilizando okara e farelo de casca de abacaxi, analisar as características físico-químicas, cor por imagem digital e análise sensorial deste produto.

\section{MATERIAL E MÉTODOS}

\section{Matéria-Prima}

Foram utilizados os seguintes ingredientes para a formulação da barra de cereais: xarope de aglutinação - açúcar mascavo, glicose de milho, gordura vegetal, aroma de baunilha e água; ingredientes secos - farelo de casca de abacaxi, farinha de okara, aveia em flocos, uva passa, flocos de arroz. A casca de abacaxi e a okara foram secos em estufa a $60^{\circ} \mathrm{C}$ durante 10 horas, depois de seco a casca foi triturada e peneirada obtendo o farelo. Para desenvolver a barra de cereais foram realizadas três formulações F1, F2 e F3, (10, 15 e 20\% de okara respectivamente) (Tabela 1), adaptadas de Arévalo-Pinedo et al. (2013). Todos os processos foram desenvolvidos no laboratório de vegetais do Campus Inhumas do Instituto Federal de Educação, Ciência e Tecnologia de Goiás.

Tabela 1. Formulação de barras de cereais elaboradas com okara e farelo de casca de abacaxi.

\begin{tabular}{lccc}
\hline Ingredientes & \multicolumn{3}{c}{ Formulações (\%) } \\
\cline { 2 - 4 } Xarope de & F1 & F2 & F3 \\
aglutinação & & & \\
Açúcar mascavo & 16,0 & 16,0 & 16,0 \\
Glicose de milho & 18,0 & 18,0 & 18,0 \\
Gordura vegetal & 2,0 & 2,0 & 2,5 \\
Aroma de baunilha & 1,0 & 1,0 & 1,0 \\
Água & 6,0 & 6,0 & 6,0 \\
& & & \\
Ingredientes secos & & & 20,0 \\
Resíduo de abacaxi & 10,0 & 15,0 & 20,0 \\
Okara & 10,0 & 15,0 & 3,0 \\
Aveia em flocos & 10,0 & 5,0 & 3,0 \\
Uva passa & 10,0 & 5,0 & 4,0 \\
Floco de arroz & 10,0 & 10,0 & \\
\hline
\end{tabular}

Fonte: Autores 


\section{Processamento das barras de cereais}

A preparação do xarope de aglutinação foi realizada em recipiente de aço inoxidável, onde os ingredientes foram aquecidos sob agitação, até a obtenção do xarope. Os ingredientes secos foram misturados ao xarope de aglutinação à temperatura de $94^{\circ} \mathrm{C}$, seguida de enformagem e prensagem, e levado ao forno a $120^{\circ} \mathrm{C}$ por dez minutos. Após resfriamento, as barras foram desenformadas e cortadas em tamanhos retangulares de $10 \mathrm{~g}$ cada unidade, e em seguida realizada a análise sensorial.

\section{Análise Sensorial}

A avaliação sensorial foi realizada por 57 julgadores não treinados, entre docentes, discentes, servidores técnicos-administrativos, terceirizados e visitantes do IFG - Campus Inhumas. A equipe abrangeu indivíduos de ambos os sexos, sendo $51 \%$ do sexo masculino e $49 \%$ do sexo feminino, com idade ente 15 e 65 anos. O procedimento ocorreu em Laboratório de Análise Sensorial do IFG - Campus Inhumas, com cabines individuais, sob luz branca.

A apresentação das amostras para análise sensorial deu-se em pratos de plástico descartável, na cor branca, codificado com códigos F1, F2 e F3. Os atributos avaliados foram: cor, sabor, consistência e impressão global. Para o teste de aceitação cada provador recebeu uma ficha de avaliação sensorial, com escala hedônica estruturada de nove pontos, abrangendo de r̃ostei muitíssimoò a r̃desgostei muitíssimoò Somente participaram dos experimentos os provadores que assinaram o Termo de Consentimento Livre e Esclarecimento (TCLE) aprovado pelo Comitê de Ética do IFG.

Para o cálculo do Índice de Aceitabilidade (IA) de cada formulação, foi utilizada a Equação (1) (TEIXEIRA et al., 1987):

Equação (1) $\quad$ IA $(\%)=A \times 100 / B$

Onde:

$A=$ nota média obtida para o produto;

$\mathrm{B}=$ nota máxima dada ao produto. 
Sendo considerada aceita a barra de cereal que apresentou IA igual ou superior a $70 \%$ (TEIXEIRA et al., 1987).

\section{Análises Físico-Químicas}

As três formulações de barras de cereais com okara e farelo de casca de abacaxi foram avaliadas quanto ao $\mathrm{pH}$, acidez titulável (AT) (\% de ácido cítrico) e sólidos solúveis totais (SST) (ㅂrix), e ratio SST/AT conforme as metodologias recomendadas pelo AOAC (2012).

\section{Cor por imagem digital}

Para a determinação da cor das barras de cereais, foi empregada câmera digital. A lente da câmara foi posicionada em perpendicular à superfície do produto a uma distância de $20 \mathrm{~cm}$ e foi ajustado o balanço de branco para luz do dia. Foi utilizado um sistema de iluminação com uma fonte D65, incidindo com ângulo de 45ำ sobre o produto colocado sobre um fundo branco. Com auxílio do programa Microsoft Paint, selecionou-se área da imagem digital das barras de cereais, aproximadamente $5 \times 5 \mathrm{~cm}^{2}$, e converteu-se a mesma em valor RGB médio, utilizando-se leitura de cor pixel a pixel do Paint. Usando a ferramenta EasyRGB, um software gratuito, os valores de RGB foram convertidos para escala CIELab, encontrando-se o valor da coordenada $L^{*}$.

\section{Análise Estatística}

Inicialmente, verificou-se se os dados atendiam às pressuposições da análise de variância, logo após, foi realizado o Teste de Tukey, utilizando-se o software livre Assistat 7.7 beta (SILVA e AZEVEDO, 2016). 


\section{RESULTADOS E DISCUSSÃO}

Os resultados das análises físico-químicas das barras de cereais acrescidas de okara e farelo casca de abacaxi estão apresentados na Tabela 2. Não houve diferença significativas entre os valores de $\mathrm{pH}$, acidez total (AT), sólidos solúveis totais (SST), e ratio SST/AT para as três formulações de barras de cereais com as porcentagens de 10, 15 e 20\% de okara e de farelo de casca de abacaxi para as formulações F1, F2 e F3, respectivamente. Indica que a variação da porcentagem destes ingredientes de uma formulação para outra não altera as características físico-quimicas do produto formulado.

$\mathrm{O} \mathrm{pH}$ variou de 5,24 a 5,55, valores bem próximos aos encontrados por Sampaio et al. (2010), que foram de 5,25 a 5,42, encontrado em barra de cerrais fortificas com ferro. Os valores de $\mathrm{pH}$ das três formulações de barras de cereais na presente pesquisa apresentaram-se relativamente baixos, indicando produto levemente ácido.

Tabela 2. pH, acidez total (AT), sólidos solúveis totais (SST), relação SST/AT de barras de cereais formuladas com okara e farelo de casca de abacaxi.

\begin{tabular}{|c|c|c|c|c|}
\hline \multirow[t]{2}{*}{ Formulação } & \multicolumn{4}{|c|}{ Características físico-químicas } \\
\hline & pH & $\mathbf{A T}^{1}$ & $\mathbf{S S T}^{2}$ & SST/AT \\
\hline $\mathrm{F} 1^{3}$ & $5,39 a \pm 0,65$ & $0,54 a \pm 0,013$ & $68,50 a \pm 1,29$ & $126,90 \mathrm{a} \pm 4,83$ \\
\hline $\mathrm{F} 2$ & $5,55 a \pm 0,69$ & $0,55 a \pm 0,016$ & $69,00 a \pm 0,81$ & $123,81 \mathrm{a} \pm 4,55$ \\
\hline F3 & $5,24 a \pm 0,45$ & $0,56 a \pm 0,011$ & $69,00 a \pm 1,41$ & $122,46 a \pm 2,77$ \\
\hline $\mathrm{CV}^{4}{ }^{4}$ & 11,33 & 2,47 & 1,75 & 3,34 \\
\hline
\end{tabular}

Fonte: Autores

A acidez total variou de 0,54 a 0,56 , sendo o menor valor encontrado na formulação F1. Estes valores corroboram com os encontrados em barras de cereais de baru analisadas por Ramos et al. (2015). Os valores de pH e acidez titulável fornecem informações quanto à qualidade do produto, visto que, quanto menor o valor de $\mathrm{pH}$ e maior o valor de acidez titulável, maior é a conversão dos ácidos graxos de cadeia longa em ácidos graxos orgânicos de cadeia curta, os quais conferem sabor e odor desagradáveis aos produtos Silva (2012). Portanto, as barras de cereais deste estudo apresentaram $\mathrm{pH}$ e acidez titulável dentro da faixa encontrada por outros autores para este tipo de produto. 
A análise de sólidos solúveis totais das barras de cereais variou de 68,50 a $69,00^{\circ}$ Brix, não havendo diferença significativa entre as formulações. Estes valores foram menores aos verificados por Gutkoski et al. (2007), em barras de cereais à base de aveia com alto teor de fibra alimentar. A relação SST/AT também não variou entre as 3 formulações. De acordo com Natividade (2010), a relação SST/AT é considerada um dos indicativos de maior importância para características do sabor de um alimento, sendo definido pelo balanço entre sólidos solúveis e acidez. Quanto maior a relação SST/AT maior a concentração de açúcares em relação aos ácidos orgânicos.

Na Figura 1 são apresentados os parâmetros da análise de cor por imagem digital das barras de cereais formuladas. Os valores evidenciam que a formulação F2 tendeu a uma coloração mais escura, pois apresentou um valor de $L^{*}$ menor.

Figura 1. Aparência das três formulações de barras de cereais elaboradas com okara (10, 15 e $20 \%$ respectivamente) e farelo de casca de abacaxi, e coordenadas de cor por imagem
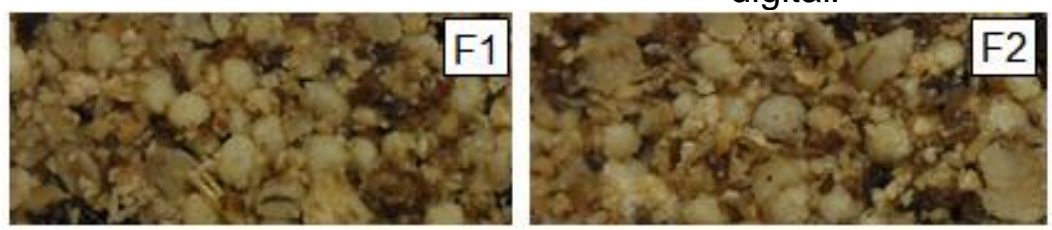

Fonte: Autores

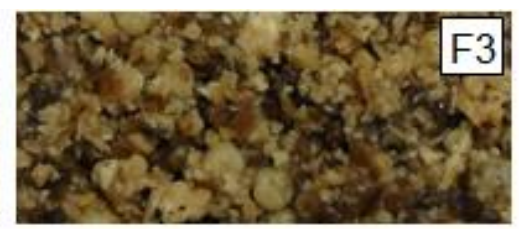

3 3

$\mathrm{Na}$ Figura 2 são apresentados os resultados obtidos no teste de análise sensorial referente à aceitação das barras de cereais elaboradas. Observou-se que todos os atributos avaliados (cor, sabor, consistência e impressão global) das formulações de barras de cereais com okara e farelo de casca de abacaxi apresentaram boa aceitabilidade, obtendo, após o teste, acima de $74 \%$ das respostas na região de aceitação (gostei a gostei muitíssimo). A formulação (F1), somando as notas de gostei, gostei muito e gostei muitíssimo, obteve maiores valores para os atributos (cor, sabor, consistência e impressão global), 92\%, 94\%, $88 \%, 95 \%$, respectivamente.

O resultado encontrado assemelha-se ao encontrado por Pertuzatti (2006), que, após avaliação das barras de cereais com mirtilo, com e sem desidratação osmótica, a maioria dos julgadores opinaram entre essas categorias de agrado. Quanto ao atributo não gostei e nem desgostei, correspondente à região de indiferença da \% escala hedônica, foram observados um percentual de respostas entre $2 \%$ a $7 \%$. E, para os atributos avaliados, não foram obtidos nenhuma resposta na região do desgostei muitíssimo. 
Figura 2. Distribuição dos provadores pelos valores hedônicos obtidos na avaliação dos atributos cor, sabor, consistência e impressão global das três formulações de barras de cereais adicionadas de okara e farelo de casca de abacaxi nas proporções de $10 \%, 15 \%$ e $20 \%$, respectivamente.

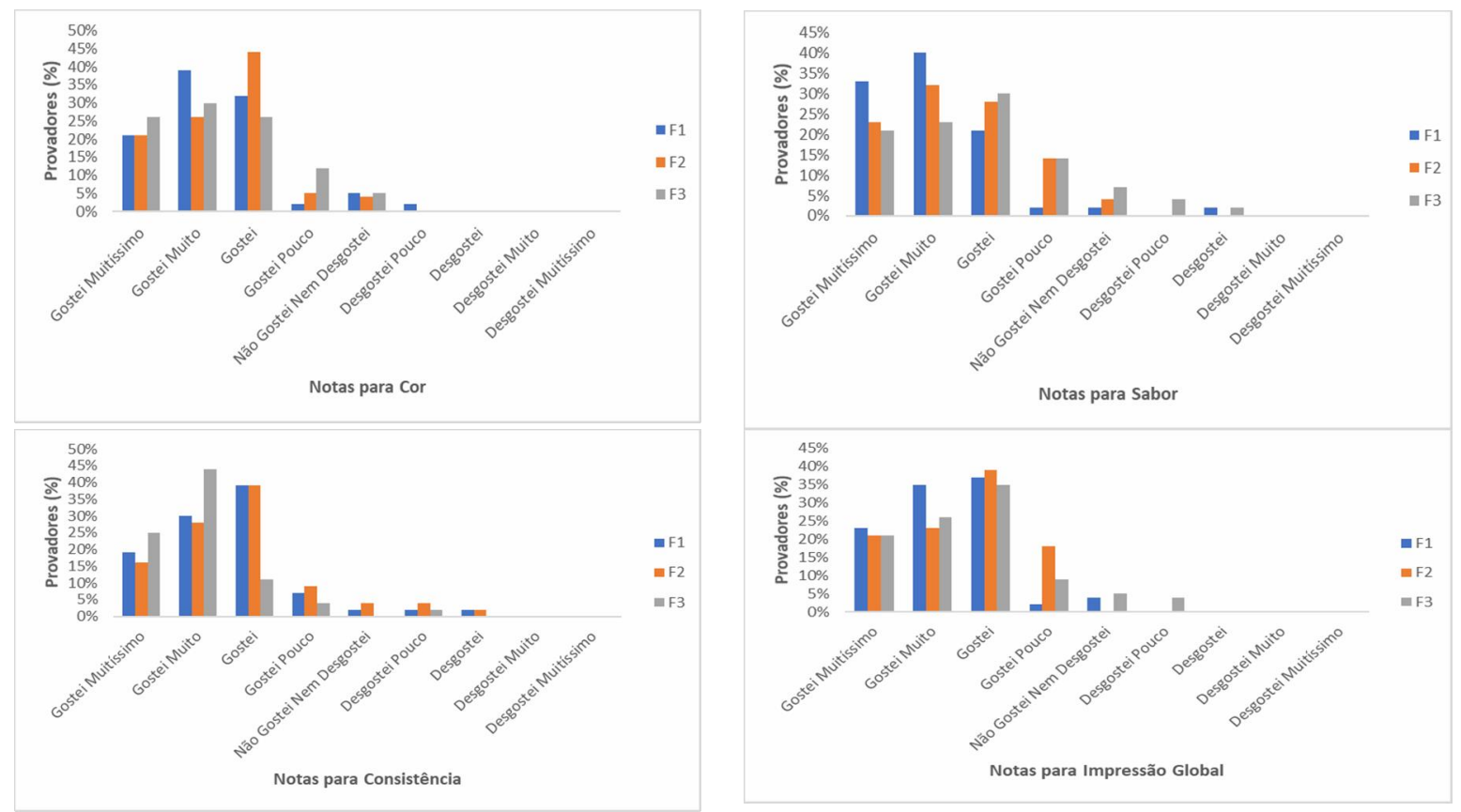

Fonte: Autores

As médias das notas atribuídas pelos 57 julgadores as barras de cereais avaliadas quanto à aceitabilidade sensorial estão apresentadas na Tabela 3. As barras de cereais elaboradas com okara e farelo de casca de abacaxi apresentaram boa aceitação nos atributos sensoriais avaliados. Pode-se observar que os julgadores não identificaram diferenças significativas entre os atributos cor, consistência e impressão global, desta forma pode-se afirmar que as três formulações (F1, F2 e F3) foram homogêneas para estes atributos. A formulação (F1) obteve maior médias de nota para os atributos cor $(7,64)$, sabor $(8,03)$, consistência $(7,45)$ e impressão global $(7,72)$, no entanto, não diferiu das formulações F2 e F3. Contudo, a formulação C diferiu significativamente da formulação A no atributo sabor.

Tabela 3. Notas atribuídas pelos provadores não treinados para a aceitação sensorial das formulações de barra de cereais formuladas com casca de abacaxi e okara.

\begin{tabular}{lcccc}
\hline Formulação & Cor $^{\top}$ & Sabor $^{\top}$ & Consistência $^{\top}$ & Impressão Global $^{{ }^{1}}$ \\
\hline F1 & $7,64 a \pm 1,06$ & $8,03 a \pm 1,11$ & $7,45 a \pm 1,25$ & $7,72 a \pm 0,99$ \\
F2 & $7,53 a \pm 0,94$ & $7,56 a b \pm 1,12$ & $7,26 a \pm 1,27$ & $7,47 a \pm 1,27$ \\
F3 & $7,58 a \pm 1,15$ & $7,26 \mathrm{~b} \pm 1,32$ & $7,14 a \pm 1,24$ & $7,37 \mathrm{a} \pm 1,24$ \\
\hline CV\% & 13,91 & 15,59 & 17,21 & 14,54 \\
\hline
\end{tabular}

Atributos avaliados; ${ }^{2}$ Médias seguidas de letras diferentes na mesma coluna diferem entre si pelo teste Tukey a $5 \%$ de probabilidade. ${ }^{3}$ Coeficiente de variação (\%).

Fonte: Autores 
Através da avaliação sensorial, verificou-se que, dentre as três formulações das barras de cereais com okara e farelo de casca de abacaxi, de acordo com o atributo sabor, as formulações F1 e F2 apresentaram a mesma aceitabilidade. O sabor é o atributo mais apreciado em um alimento, nas três formulações a que obteve a maior nota foi a $(F 1)$ e esta não diferiu da $F 2$, comprovando que as formulações F1 e F2 foram as mais aceitas pelos julgadores.

O Índice de Aceitabilidade (IA) verificado para as três formulações de barras de cereais foi significativo, considerando uma repercussão favorável quanto ao IA. Segundo Bispo et al. (2004), Teixeira et al. (1987) e Dutcosky (2007), para que o produto seja considerado como aceito, em termos de suas propriedades sensoriais, é necessário que este obtenha um Índice de Aceitabilidade (IA) de, no mínimo, 70\%. Para a formulação (F1), o IA variou de $82,77 \%$ a $89,22 \%$ para os atributos avaliados, com destaque para o atributo cor. Já a formulação (F2), variou entre $80,66 \%$ a $84,00 \%$, e a formulação (F3) 79,33\% a 84,22\%, para esta formulação a consistência obteve uma menor porcentagem para o IA (Tabela 4).

Ao desenvolver um novo produto, um dos pontos fundamentais é avaliar sua aceitabilidade, a fim de predizer seu comportamento frente ao mercado consumidor (MOSCATTO et al., 2004). Com base nas notas para a aceitabilidade e no cálculo do IA, pode-se verificar que todas as formulações apresentaram boa aceitabilidade, visto que as formulações avaliadas apresentaram IA superior a $79,3 \%$ para todos os atributos avaliados.

Tabela 4. Índice de aceitabilidade (IA) das barras de cereais formuladas com okara e farelo de abacaxi segundo atributo avaliados.

\begin{tabular}{lccc}
\hline Formulação & Atributos & Notas Médias & Índice de Aceitabilidade (\%) \\
\hline \multirow{2}{*}{ F1 } & Cor & 7,64 & 84,88 \\
& Sabor & 8,03 & 89,22 \\
& Consistência & 7,45 & 82,77 \\
& Impressão Global & 7,72 & 85,77 \\
\hline \multirow{2}{*}{ F2 } & Cor & 7,53 & 83,66 \\
& Sabor & 7,56 & 84,00 \\
& Consistência & 7,26 & 80,66 \\
& Impressão Global & 7,47 & 83,00 \\
\hline \multirow{2}{*}{ Coor } & Sabor & 7,58 & 84,22 \\
& Consistência & 7,26 & 80,66 \\
& Impressão Global & 7,14 & 79,33 \\
& & 7,37 & 81,88 \\
\hline
\end{tabular}

Fonte: Autores

A análise sensorial é uma ferramenta que é utilizada para o desenvolvimento de novos produtos, determinação das diferenças e similaridades apresentadas entre 
produtos concorrentes, reformulação de produtos já estabelecidos no mercado, estudo de vida de prateleira (shelflife), identificação das preferências dos consumidores por um determinado produto e, finalmente, para a otimização e melhoria da qualidade (SCHNEIDER, 2006). Na presente pesquisa sensorial, mostrou-se um índice de aceitabilidade superior ao preconizado de $70 \%$, indicando que as formulações foram aceitas pelos julgadores.

\section{CONCLUSÃO}

As barras de cereais formuladas com okara e farelo de abacaxi foram bem aceitas pelos julgadores, potenciais consumidores desde tipo de produto. Portanto, percebe-se a relevância destas formulações, tornando-as promissoras e inovadoras, principalmente por utilizarem resíduos na sua formulação. Por outro lado, cria-se a possibilidade de aproveitamento desses resíduos na alimentação humana.

\section{Referências}

AOAC. American of Official Analytical Chemists. Official methods of analysis of AOAC. 19. Ed. Gaitlerburg: AOAC International. 2012.

APLEVICZ, K. S.; DEMIATE, I. M. Análises Físico-Químicas de Pré-Mistura de Pães de Queijo e Produção de Pães de Queijo com Okara. Revista Ciência e Agrotécnica, Lavras, 2007.

ARÉVALO-PINEDO, A.; ARÉVALO, Z. D. S.; BESERRA, N. S.; ZUNIGA, A. D. G.; COELHO, A. F. S.; PINEDO, R. A. Desenvolvimento de barra de cereais à base de farinha de amêndoa de babaçu (Orbygnia speciosa). Revista Brasileira de Produtos Agroindustriais, v. 15, n. 4, p. 405-411, 2013.

BISPO, E. S.; SANTANA, L. R. R.; CARVALHO, R. D.S.; LEITE, C. C; LIMA, M. A. C. Processamento, Estabilidade e Aceitabilidade de Marinado de Vongole. Ciência e Tecnologia de Alimentos, v. 24, n. 3, p. 353-356, 2004.

DUTCOSKY, S. D. Análise sensorial de alimentos. Curitiba: Champagnat, 2007.

FONSECA, R. S.; DEL SANTO, R.; SOUZA, G. B., PEREIRA, C. A. M.; Elaboração de barra de cereais com casca de abacaxi. Archivos Latinoamericanos de Nutrición, v.61, 2011. 
GRDEN, L.; DE OLIVEIRA, C. S.; BORTOLOZO, E. A. F. Q. Elaboração de uma barra de cereais como alimento compensador para praticantes de atividade física e atletas. Revista Brasileira de Tecnologia Agroindustrial, v. 2, n. 1, 2008.

GUTKOSKI, L. C., BONAMIGO, J. D. A., TEIXEIRA, D. D. F.; PEDÓ, I. Desenvolvimento de barras de cereais à base de aveia com alto teor de fibra alimentar. Ciência e Tecnologia de Alimentos, v. 27, n. 2, p. 355-363, 2007.

IZZO, M.; NINESS, K. Formulating Nutrition Bars with Inulin and Oligofructose. Cereal Foods World, v. 46, n. 3, p. 102-105, 2001.

LOBATO, L. P.; IAKMIU, C.; PEREIRA, A. E.; LAZARETTI, M. M.; BARBOSA, D. S.; CARREIRA, C. M.; MANDARINO, J. M. G.; GROSSMANN, M. V. E. Snack bars with high soy protein and isoflavone content for use in diets to control dyslipidaemia. International journal of food sciences and nutrition, v. $63, \mathrm{n}$. 1, p. 49-58, 2012.

MOSCATTO, J. A.; PRUDÊNCIO-FERREIRA, S. H.; HAULY, M. C. O. Farinha de yacon e inulina como ingredientes na formulação de bolo de chocolate. Ciência e Tecnologia de Alimentos, Campinas, v. 24, n. 4, p. 634-640, 2004.

NATIVIDADE, M. M. P. Desenvolvimento, caracterização e aplicação tecnológica de farinhas elaboradas com resíduos da produção de suco de Uva. 2010. 202 p. Dissertação (Mestrado em Ciência dos Alimentos) ï Universidade Federal de Lavras, Lavras, 2010.

PAIVA, A. P. Estudo tecnológico, químico, físico-químico e sensorial de barra de alimentícias elaboradas com subprodutos e resíduos agroindustriais. Dissertação de mestrado da Universidade de Lavras Minas Gerais, 2008.

PAULA, G. T.; FARIAS, H. P. S.; ALI, L. R. F. Y.; RIBEIRO, R. C.; SILVA PEREIRA, V.; SOUZA PAIVA, E.; PEREIRA, M. C. P. C. Desenvolvimento de uma formulação do ñtipo hambúrgueròde okara com shitake. Semioses, v. 13, n. 1, p. 33-46, 2019.

PERTUZATTI, P. B.; CORRÊA, F. V.; DE MORAES, J. O.; SALAS-MELLADO, M.; SANTOS, R. O. Avaliação sensorial de barras de cereais com passas de mirtilo (vaccinium ashei reade) com e sem desidratação osmótica. In: Congresso de Iniciação científica da Universidade Federal de Pelotas, 15, 2006, Pelotas. Resumos... Pelotas: UFPEL, 2006.

PRADO, I. D.; LALLO, F. H.; ZEOULA, L. M.; CALDAS, S. F.; DO NASCIMENTO, W. G.; MARQUES, J. Níveis de substituição da silagem de milho pela silagem de resíduo industrial de abacaxi sobre o desempenho de bovinos confinados. Revista Brasileira de Zootecnia, Viçosa, v. 32, n. 3, p. 737-744, 2003.

RAMOS, E. W. V. B.; SOUZA, L. F. A.; LIMA, A. V. S. C.; SANTOS, M. R. L. Qualidade físico-química e microbiológica de barras de cereais de baru 
adquiridas em Pirenópolis-Go. IV Congresso Estadual de Iniciação Científica do IF Goiano, p. 1-2, 21 a 24 de setembro de 2015.

RODRIGUES JUNIOR, S.; PATROCINIO, I. M.; PEÑA, W. E. L.; JUNQUEIRA, M. S.; QUINTÃO TEIXEIRA, L. J. Q. T. Desenvolvimento de barra de cereal salgada enriquecida com farinha de albedo de maracujá. Enciclopédia Biosfera, Goiânia, v. 7, n. 12, p.1-7, 2011.

SAMPAIO, C. R. P.; FERREIRA, S. M. R.; CANNIATTI-BRAZACA, S. G. Caracterização físico-química e composição de barras de cereais fortificadas com ferro. Brazilian Journal of Food \& Nutrition, v. 21, n. 4, 2010.

SCHNEIDER, F. Análise Sensorial para bebidas lácteas fermentadas. SENAI ï RS, 2006.

SILVA, J.S. Barra de cereais elaboradas com farinha de semente de abóbora (dissertação). Lavras, MG: Programa de Pós Graduação em Agroquímica, Universidade Federal de Lavras; 2012.

SILVA, F. A. S.; AZEVEDO, G. A. V. The Assistat Sofware Version 7.7 and its use in the analysis of experimental data. African Journal Agricultural Research, v.11, n.39, p.3733-3740, 2016.

SILVA, T. S.; SANTOS, D. C.; PEREIRA, M. M.; BARBOSA, M. I. M. J.; Na natureza nada se perde tudo se transforma: ñAproveitamento de okara, resíduo agroindustrial da soja, na elaboração de cereal matinal.ò Centro Federal de Educação Tecnológica em Química de Nilópolis, Maracanã, RJ, 2007.

SOUZA, D. G.; GEBRIM, L. C.; PLÁCIDO, G. R.; FURTADO, D.C.; OLIVEIRA K. B.; MOURA, L. C. Elaboração de barras de cereais com adição de sementes de gergelim. In: I Congresso de Pesquisa e Pós-Graduação do Câmpus Rio Verde do IF-Goiano. Anais... 06 e 07 de novembro de 2012.

TEIXEIRA, E.; MEINERT, E.; BARBETA, P. A. Análise sensorial dos alimentos. Florianópolis: UFSC, $1987.182 \mathrm{p}$. 